\title{
Todo dia era dia de índio: manifestações culturais relativas à semana do dia do índio nas Terras Indígenas de Chapecó, Santa Catarina, Brasil
}

\author{
Adiles Savoldi \\ Professora de antropologia da Universidade Federal da Fronteira Sul \\ adiles@uffs.edu.br
}

Resumo: A proposta deste artigo é a reflexão sobre os múltiplos planos que articulam as atividades desenvolvidas nos últimos anos, por ocasião do dia 19 de abril, em terras indígenas do Sul do Brasil, mais especificamente em Chapecó, SC. A Terra Indígena Toldo Chimbangue está localizada às margens dos rios Irani e Lajeado Lambedor, a uma distância de $18 \mathrm{~km}$ da cidade de Chapecó, já a Terra Indígena Reserva Aldeia Condá localiza-se na linha Gramadinho, a $15 \mathrm{Km}$ da área urbana de Chapecó. A etnografia desenvolvida procurou mapear as diferentes etapas, estratégias e significados da preparação e realização da Semana Cultural. A observação participante nas atividades culturais aconteceu desde 2004 até 2012. A Semana Cultural, manifestação pública relativa ao dia do indio, nas Terras Indígenas de Chapecó foi e é ainda organizada pelos professores das Escolas Indígenas de Ensino Fundamental das respectivas Terras indígenas. Durante a Semana acontecem apresentaçães de danças, exposição de artesanato, degustação de culinária típica; é o momento do encontro entre a população indígena e os visitantes, contexto que se constitui em um espaço de negociações de sentidos e trocas culturais. Os professores indígenas acreditam que a Semana Cultural é a possibilidade de mostrar com dignidade a versão da bistória do ponto de vista Kaingang, deste modo, a cultura passa a ser positivada e valorizada num contexto em que historicamente foi negativada e desvalorizada.

Palavras-chave: Kaingang, educação indígena diferenciada, turismo étnico, turismo cultural.

Abstract: The aim of this article is to reflect on the multiple issues articulated by the activities that have been beld in recent years to celebrate the 19th of April in the indigenous lands of the Southern Region of Brazil, specifically in Chapecó, SC. The Toldo Chimbangue Indigenous Land is located between the rivers Irani and Lajeado Lambedor, $18 \mathrm{~km}$ from the town of Chapecó, and the Aldeia Condá Reserve is located on the Gramadinho line $15 \mathrm{Km}$ 
from Chapecó. The ethnographic study has aimed to record the different stages, strategies and meanings of the preparations for the Cultural Week. Participant observation in the cultural activities was carried out from 2004 to 2012. The Cultural Week is a public celebration relating to Indian Day and, in the Indigenous Lands of Chapecó it was and still is organized by teachers from the Indigenous Schools of Basic Education of the respective indigenous territories. During the Cultural week there are dances, art exhibitions, tastings of local foods, etc., and there is the opportunity for encounters between the indigenous population and visitors in the context of a space where senses can be negotiated and cultural exchanges can take place. The indigenous teachers state that the Cultural Week enables them to give, in a dignified manner, a version of history from the point of view of the Kaingang, which in turn allows their culture to be positively perceived and evaluated in a context in which it has bistorically been undervalued and disparaged.

Keywords: Kaingang, differentiated indigenous education, ethnic tourism, cultural tourism. 


\section{Introdução}

As comemorações relativas ao dia do índio, tradicionalmente realizadas na semana do dia 19 de abril, vêm se constituindo em espaços de visibilidade e positividade da cultura Kaingang. A proposta foi refletir sobre a realização da Semana Cultural e os encontros dela decorrentes. No Toldo Chimbangue há a presença do povo Guarani, no entanto, a análise privilegiou a cultura Kaingang.

Por meio da etnografia procurei mapear as diferentes etapas, estratégias e significados da preparação e realização da Semana Cultural. A observação participante nas semanas culturais aconteceu desde 2004 até 2012. Além das entrevistas com os organizadores e visitantes, outra fonte de pesquisa foi o acervo do CEOM (Centro de Organização da Memória do Oeste de Santa Catarina) relativo às Semanas Culturais realizadas nos anos anteriores.

A denominação Kaingang foi cunhada por Borba (1908), no final do século xıx. Segundo Veiga (1995) a denominação Kaingang é genérica e aborda grupos indígenas falantes de dialetos de uma mesma língua, filiados ao tronco Jê, localizados nos Estados de São Paulo, Paraná, Santa Catarina e Rio Grande do Sul, bem como na província argentina de Missiones. D’Angelis (1995) revela que o avanço das frentes pastoris no território Kaingang tornou-se sistemático somente no início do século XIX, "em razão da economia portuguesa e em função da geopolítica colonial" (ibidem, p. 154).

No final do século xix, com a queda do Império e o estabelecimento da República por parte dos militares, foi promulgada, em 1891, a Constituição Republicana. A Constituição marcou uma mudança no modo de administração da terra, "as terras devolutas do Império são entregues ao domínio dos Estados, que ficam com o direito de medi-las, doá-las, etc.” (D’Angelis, 1995, p.187). Segundo o autor, inúmeros aldeamentos foram tomados dos índios no período.

No início do século xx, o Governo de Santa Catarina investiu na política de colonização, no recém-incorporado oeste catarinense, o alvo foi os descendentes de imigrantes europeus que haviam se estabelecido no Rio Grande do Sul, no final do século Xıx, e que no momento precisavam de novas terras. As maiores investidas na área do Chimbangue aconteceram na década de 40, tendo como protagonista a empresa Luce Rosa \& Cia, que comprou as terras dos herdeiros da Baronesa de Limeira. 
Segundo Bloemer e Nacke (2007), a ineficácia do SPI (Serviço de Proteção ao Índio) na proteção e regularização da área indígena possibilitou que a empresa Luce \& Rosa efetivasse a venda da terra a Severino e Giocondo Trentin, que, por sua vez, revenderam para os colonos, descendentes de imigrantes europeus, mais especificamente de italianos e alemães, oriundos do Rio Grande do Sul.

Há registros da presença Kaingang no Chimbangue desde 1882. No final da década de 1970, os Kaingang se organizam na luta pela retomada das terras. Segundo Bloemer e Nacke (2007), em 1985, foram demarcados 988 hectares, metade da área reivindicada pelos Kaingang do Toldo Chimbangue.

Segundo Fernandes (2003) o processo de criação da Reserva Indígena Aldeia Condá iniciou em 1998, com a constituição de grupo técnico da Funai para a elaboração do Relatório de Identificação das Famílias Kaingang Residentes na Cidade de Chapecó. Tal relatório foi coordenado pela antropóloga Kimiye Tommasino. O documento demonstrou que os Kaingang da Aldeia Condá reconheceram a cidade de Chapecó como seu território tradicional. Conforme Fernandes (2003),

Diante destas conclusões ficou estabelecido que seria impossível recuperar a terra tradicional desses Kaingang. Sendo assim, a Funai procedeu à constituição de um Grupo Técnico para a eleição de uma terra para a criação da Reserva Indígena Aldeia Condá. Assim, foi eleita área de 2.300,2 hectares na zona rural do município de Chapecó. Os critérios básicos da escolha da área eleita focalizaram: (1) o estabelecimento de limites naturais; (2) as condições agro-ecológicas para conciliar produção familiar com desenvolvimento da mata, articulando agricultura e coleta; (3) a proximidade estratégica do núcleo urbano para a continuidade das relaçóes socioeconômicas já estabelecidas no município de Chapecó; e (4) a preferência por terras ocupadas por pequenos produtores rurais, a fim de evitar conflitos com grandes produtores rurais influentes na política local e, notoriamente, avessos à presença dos indígenas. (Fernandes, 2003, p. 199).

Antes da definição do espaço para a criação da Reserva Aldeia Condá, os kaingang, viviam precariamente em barracos de lona, no bairro Palmital, na cidade de Chapecó. Segundo Nacke e Bloemer (2007), os Kaingang sempre estiveram no centro de Chapecó, mas devido ao crescimento da cidade na década 
de 1990, a presença Kaingang se tornou mais visível e inconveniente por vários órgãos públicos. A população local os acusou/acusa de sujos, preguiçosos.

Foram realizadas inúmeras investidas para encaminhar a população Kaingang para outras áreas indígenas de Santa Catarina e Rio Grande do Sul, no entanto, em pouco tempo, muitos acabavam retornando, o que caracteriza o fato da cidade constituir um território Kaingang.

Segundo as informações do relatório desenvolvido por Tommasino (1998), a memória Kaingang identifica o espaço central da cidade de Chapecó, a praça e a catedral, como locais onde acontecia o ritual do Kiki, ritual de culto aos mortos.

No ano de 2011, foi construído, na Reserva Aldeia Condá, um espaço para a realização do ritual do Kiki. A proposta do espaço está em consonância com o projeto da Escola Indígena, que desenvolve o projeto de "revitalização da cultura".

Para os descendentes de imigrantes europeus no oeste de Santa Catarina, o que legitima a posse da terra é o trabalho. A expressão mais comum, neste sentido, é "pra que os índios querem tanta terra se eles não trabalham?" Os discursos mais simplistas sobre os índios não são inéditos, tampouco exclusivos da região oeste, eles repetem um repertório já abordado por autores como Oliveira (1998), entre outros.

$\mathrm{Na}$ análise de Bourdieu (1989), a região não é apenas o espaço, mas constitui-se no compasso deste com o tempo e a história. O autor afirma que "o discurso regionalista é um discurso performático" (ibidem, p.116). Nos discursos regionalistas ocultam-se índios e caboclos como sujeitos construtores da história, somente os descendentes de imigrantes europeus aparecem como os trabalhadores que fazem da região uma terra de progresso. A esse respeito, Bourdieu (1989) argumenta que somente os grupos que dispóem de autoridade legítima, ou melhor, de autoridade creditada pelo poder podem impor suas próprias definições de si mesmos e dos outros. Os diferentes grupos étnicos se encontram em diferentes posições de poder. Os descendentes de imigrantes europeus acionam o trabalho como um sinal diacrítico para estabelecer a distinção com os outros grupos étnicos. Eles se autonominam como trabalhadores em relação aos outros, que são classificados etnocentricamente como pessoas de valor menor, avessas ao trabalho (Savoldi, 2006). 


\section{A visibilidade das diferenças e as fronteiras étnicas}

Os símbolos que estão sendo privilegiados para representar o modo de vida Kaingang, na atualidade, nas Terras Indígenas de Chapecó, são construídos em oposição às representações estereotipadas da população não-índia.

As relações interétnicas se constituem relacionalmente neste contexto onde a disputa não acontece apenas em relação à terra, mas também nas diferentes formas de expressar o mundo. Para Barth (1969), etnicidade reflete a forma com que o grupo mantém simbolicamente as suas fronteiras culturais. Nesta perspectiva, as identidades não são concebidas como resultados de heranças culturais, e sim resultados de uma invenção contínua de traços culturais. A identidade, portanto, pode ser representada como um jogo simbólico. As fronteiras étnicas são definidas a partir das diferentes formas de organizar a diferença.

Lac (2005, p.16), ao analisar o turismo e a identidade indígena, faz referência à fronteira étnica concebida, segundo Nunes (2004), como sendo "ao mesmo tempo, um ponto de éncontro e de desencontro' dos grupos sociais em decorrência de conflitos diversos, especialmente de identidade". Os principais conflitos, no presente, dizem respeito à luta pela terra. Conforme entrevista com professora Kaingang,

No contexto atual, a luta pela terra, para nós Kaingang do Toldo Chimbangue, simboliza, também, a luta pela sobrevivência e pela manutenção de nossa especificidade cultural. (Professora Kaingang Janete da Veiga)

Os Kaingang da Terra Indígena (TI) Chimbangue são concebidos pela alteridade, em muitas circunstâncias, de modo pejorativo e algumas vezes são acusados de roubar terras dos agricultores. É nesse contexto que o povo Kaingang abre as suas portas para receber os visitantes na comemoração da semana do dia do índio.

A escolha do dia 19 de abril para comemorar o dia do Índio aconteceu no I Congresso Indigenista Interamericano, realizado no México em 1940. Getúlio Vargas estabeleceu a data comemorativa através do Decreto-Lei n. 5.540, na cidade do Rio de Janeiro, em 2 de junho de 1943. Foi o General Cândido Ma- 
riano Rondon quem protagonizou a comemoração instituindo uma semana do índio.

Hoje, as atividades culturais são organizadas pelo próprio povo indígena, coordenada pela proposta de uma educação diferenciada. $\mathrm{Na}$ contemporaneidade, a diferença se constitui em um referencial que adquire o estatuto do direito, contrariando as hipóteses globalizantes que alardeavam o seu fim. Com a promulgação da Constituição Federal de 1988, os povos indígenas conquistam o direito de um currículo diferenciado. A especificidade do currículo permite o ensino da língua materna e outras práticas culturais que vêm sendo pesquisadas pelos professores indígenas.

De acordo com Nötzold (2003), em 31 de março de 1995 foi criado o NEI (Núcleo de Educação Indígena) junto à Secretaria do Estado da Educação e do desporto de Santa Catarina. Esse núcleo foi o responsável pelas propostas educacionais diferenciadas. $\mathrm{O}$ objetivo do projeto de educação diferenciada expressa: "a educação escolar indígena deve ser intercultural e bilíngüe, específica e diferenciada"1.

A possibilidade de construção de currículos específicos que levassem em consideração as diferenças culturais e lingüísticas propiciou uma reflexão por parte dos próprios professores das terras indígenas. A responsabilidade em estabelecer os contornos, as fronteiras das diferenças, foi o grande desafio dos professores Kaingang.

Para analisar as diferenças culturais, remeto a Geertz (1989), que concebe a cultura como um conjunto de símbolos e significados estabelecidos socialmente. O conceito de cultura "tem seu impacto no conceito de homem. Quando vista como um conjunto de mecanismos simbólicos para controle do comportamento, fontes de informação extra-somáticas, a cultura fornece o vínculo entre o que os homens são intrinsecamente capazes de se tornar e o que eles se tornam, um por um" (Geertz, 1989, p.64). As teias de sentido produzidas pela cultura orientam a conduta, comportamentos e também constroem o homem. $\mathrm{O}$ homem do mesmo modo que produz cultura também é produzido pela cultura. A cultura é o conjunto de significados através dos quais os homens dão forma à sua experiência.

1. Folder sobre o curso de formação e habilitação de professores de $1^{\circ}$ a $4^{\circ}$ de ensino fundamental para o contexto Xokleng e Kaingang. 
O projeto de educação diferenciada trouxe à tona uma discussão e negociação interna sobre o que é considerado relevante, específico e diferente em relação ao contexto Kaingang. $\mathrm{O}$ que é ser índio?

Ser índio é ter raízes indígenas. Precisamos ter em mente a importância da nossa cultura e não ter vergonha de nos identificar quando preciso for. Precisamos lutar pela nossa própria identidade sempre respeitando as outras pessoas [...] Bom, no modo de eu ver, ser índio, hoje, é preservar a minha cultura, conhecer o meu sistema, modo de viver, de pensar, modo de trabalhar, mas também conhecendo outro mundo, hoje é preciso ter os dois mundos, entender os dois mundos, para a gente poder sobreviver, porque se eu ficar hoje só na minha cultura, eu não acompanho, daqui a pouco eu vou ficar para trás, vou sofrer, então, hoje, a gente tem a nossa escola para instruir, dar instruções, buscar o conhecimento. (Professor Kaingang, Valmor Venhrá Mendes de Paula).

A educação diferenciada, para os professores indígenas, possibilita trabalhar com os alunos indígenas a valorização e a positividade de cultura Kaingang. Tem como meta conhecer a cultura dos antepassados, "preservar" essa cultura, sem deixar de conhecer e se informar sobre o que está acontecendo no mundo.

\section{A educação revelando e construindo diferenças}

De acordo com Nötzold (2003), o NEI (Núcleo de Educação Indígena) foi criado com o objetivo de sistematizar estudos para viabilizar o currículo diferenciado. Uma das principais dificuldades que o NEI teve que enfrentar foi o desinteresse dos alunos em aprender a língua Kaingang.

A implantação de projetos escolares diferenciados para sociedades indígenas apresentava, entretanto, um grave porém. No artigo 210 da Constituição Federal, tiveram assegurados a utilização das línguas maternas, com processos próprios de aprendizagem, entretanto em alguns casos a comunidade já não utilizava a língua materna cotidianamente, sendo necessário criar a figura do monitor-bilíngüe, surgindo assim para alfabetizar nas línguas indígenas. (Nötzold, 2003, p.31).

Para a autora, a resistência da retomada da língua foi manifestada tanto pelos pais como pelos alunos, sendo superada "aos poucos, graças à perseverança 
dos professores" (ibidem, p.31). No projeto de educação diferenciada, é fundamental a presença de professores indígenas na recuperação da língua. Nos moldes da educação formal, o currículo não apresentava as especificidades da cultura Kaingang; do mesmo modo, os professores desconheciam muito das características da cultura. A proposta de educação diferenciada oportunizou uma valorização da identidade Kaingang, conforme a afirmação da professora Vanisse Domingos:

A etnia Kaingang foi, ao longo da história, discriminada, excluída e esquecida pela sociedade envolvente. Foi, muitas vezes, obrigada a esquecer sua cultura, para, assim, ser aceita na sociedade. Como forma de luta e retomada de seus direitos, conquistas; iniciou-se com os povos indígenas o trabalho de revitalização da cultura; aqui no Sul, em específico, os Kaingang.

A dança Kaingang é uma forma de revitalização da cultura; para isso, foram necessárias muitas pesquisas, principalmente com nossas pessoas mais velhas da comunidade, que para nós são os nossos laboratórios de aprendizagem.

Hoje a dança Kaingang está muito presente em todas as manifestaçóes culturais da Terra Indígena; cada uma possui um significado para a etnia Kaingang, que está dia-a-dia lutando para a concretização e o respeito de seus direitos, que muitas vezes são mal interpretados pela sociedade. (Professora Kaingang, Vanisse Fágkri Domingos).

As pessoas mais velhas são consideradas fundamentais na nova proposta educacional. São uma das principais fontes de informação sobre o passado, sobre os modos de vida que se quer "revitalizar hoje". Outra característica da educação diferenciada são os conteúdos considerados apropriados para compor o currículo, como, por exemplo, danças, artesanato.

Os professores reivindicam, hoje, um calendário diferente, alegam que construir uma proposta diferenciada orientada por um calendário que não leva em consideração os seus feriados, suas datas significativas, é um contra-senso. Em relação à cultura diferenciada, advertem que há muita coisa a ser feita ainda, conforme argumenta o professor indígena Valmor:

Nós professores precisamos estar nos atualizando, trocando experiências com as demais escolas. Porque o nosso trabalho de línguas, nós não temos o 
suporte pedagógico, nós não temos porque, até então, não temos material didático, o material didático que nós temos é aquele que nós construímos dentro da escola, e só, ou experiências que fizemos em outras escolas também. (Professor Kaingang, Valmor Venhrá Mendes de Paula).

Como esse projeto é ainda novo, falta uma assessoria pedagógica e uma assessoria na produção do material didático. Outras dificuldades são apontadas na ausência da matéria-prima para a produção do artesanato:

A gente deixou de buscar coisas que poderiam ser mais representativas, de mais representatividade, de trabalhos feitos por nós, mas que, por falta de dinheiro, muitas vezes se deixou de adquirir, porque hoje nem tudo a gente consegue na natureza. Tinta, precisamos de tinta, temos que buscar na cidade, precisamos de barbante, para fazer um colar, temos que buscar na cidade porque na mata onde tinha cipó que a gente fazia o barbante não tem mais, praticamente ficou escasso, matéria-prima tá em extinção a cada ano que passa, e a gente tá envolvendo toda a piazada, para que, a partir deste ano, mais tarde no início do ano que vem, a gente possa também cultivar matéria-prima. (Professor Kaingang, Valmor Venhrá Mendes de Paula).

Mesmo que a proposta seja "revitalizar" a cultura, é possível perceber que a cultura "ideal" precisa encontrar a natureza adequada; percebe-se que não foi apenas a cultura que mudou, a natureza já não é a mesma do tempo dos mais velhos.

Com a proposta de uma educação diferenciada surgiu, também, a possibilidade da revitalização da cultura. Para a execução dessa educação diferenciada, foi necessário estudar, discutir e rememorar o passado para pensar a "diferença" a ser destacada no presente. Os resultados da educação diferenciada vêm sendo divulgados a partir de 2000, com a organização da primeira Semana Cultural. Segue o relato da professora Kaingang Janete da Veiga sobre a organização da primeira Semana Cultural,

A partir de 2000, a comunidade se reuniu e começou a desenvolver apresentações que mostravam como é, de fato, a cultura indígena. A primeira iniciativa foi na Escola de Ensino Fundamental Irani, que atendia de primeira a quarta série, na década de noventa, que não teve nenhum registro. No ano de 2000 , na Escola Básica Sede Trentin, o coletivo de professores uniu-se junto à co- 
munidade indígena e iniciou a Semana Cultural. (Professora Kaingang, Janete da Veiga $)^{2}$.

A preparação da Semana Cultural já faz parte do currículo e calendário da Escola. A programação é divulgada num folder para as instituições de ensino e o público em geral. Não há restrições no que diz respeito à entrada na Terra Indígena durante a realização do evento. As Escolas de Chapecó e cidades vizinhas costumam agendar as visitas.

A Semana Cultural, em 2002, teve como tema: "Os kaingang do Toldo Chimbangue, revitalizando sua história e construindo sua autonomia em defesa dos seus direitos". O objetivo da II semana foi:

Levar ao conhecimento da sociedade envolvente a luta dos povos indígenas em busca da revitalização das suas culturas, fazendo a integração e exposição das etnias kaingang e Guarani, mostrando à sociedade não-índia um conhecimento amplo da realidade indígena e passando a ter uma nova visão sobre a nossa cultura, aprendendo a respeitá-la e valorizá-la.

Outra Semana Cultural apresentou o tema: "Não somos atrasados, Kaingang, estamos cultivando o passado; vivendo e construindo no presente preparando-nos para o futuro". Os protagonistas e participantes argumentam que a organização da Semana Cultural vem sendo aprimorada com o decorrer do tempo. Os temas das semanas evidenciam a tentativa de influenciar o público para que este ouça a história sob o ponto de vista da cultura Kaingang: "O objetivo é que os não-índios nos vejam como seres humanos e nos tratem com respeito" (Professor Kaingang, João Batista).

A abertura da Semana Cultural acontece com a presença e discurso das autoridades locais, lideranças indígenas, representantes do município e professores indígenas. Após os discursos iniciais, a banda do Batalhão Militar se apresenta com o Hino Nacional. Em seguida, as crianças da Escola Fen’Nó cantam o Hino Nacional em língua Kaingang. Na seqüência, o evento segue a programação anunciada no folder.

Os meios de comunicação fazem cobertura do evento, contribuindo para divulgar as atividades. Segundo a professora Kaingang Janete da Veiga, o espaço de diálogo que a semana possibilita tem sido a oportunidade de a população Kaingang expressar a sua versão dos fatos.

2. Texto apresentado no relatório da Semana Cultural de 2006. 
Pois na sociedade nacional os indígenas têm encontrado grandes dificuldades de se comunicar e se relacionar [...] A discriminação, em pleno século XXI, em relação a nós Kaingang e aos demais grupos indígenas nos impressiona e nos leva a refletir sobre a necessidade de construir novas bases de diálogo e de relações que visem garantir mais tolerância nas práticas e referentes ao respeito com as diferentes culturas no Brasil e no mundo. ${ }^{3}$

O turismo propicia a reflexão sobre a história, símbolos e significados que são construídos e reconstruídos a partir das relações sociais. Na contemporaneidade, a espetacularização das diferenças tem revelado uma busca frenética pela singularidade dos grupos, lugares, histórias. Segundo Steil (2004), o encontro entre nativos e turistas se constitui em um espaço de negociações e trocas culturais.

Os professores indígenas consideram positiva a visita dos não-índios à terra indígena, conforme depoimento abaixo:

O que a gente pensa é que certamente as pessoas vêm pra conhecer a verdadeira história nossa, e valorizando, procurando se inteirar melhor da história verdadeira, porque, até então, a história contada sobre os indígenas muitas coisas não são verdadeiras, e hoje a gente tá recriando a nossa verdadeira história, para que ela passe a mostrar o lado certo da história, que foi contada por um não-Índio, e que tá sendo contada pelos próprios Índios. (Professora Kaingang, Janisse Domingos).

Neste artigo, não analiso a especificidade de cada Semana Cultural, mas seleciono aspectos relevantes dos anos da realização da etnografia. Em cada Semana Cultural, acontecem exposições de trabalhos pedagógicos dos alunos. Os trabalhos são organizados com o objetivo de dar visibilidade à história e à cultura Kaingang. Todas as atividades selecionadas são disponibilizadas em salas de aula para a visitação dos turistas, sempre acompanhas de um monitor que responde às perguntas. A maioria dos monitores são professores e alunos Kaingang. Em uma das salas de aula havia uma maquete do cemitério Kaingang, com a respectiva distribuição das metades clânicas Kamé e Kairu. O monitor que prestava esclarecimentos disse ser professor de matemática, e que, embora não fosse índio, trabalha há muito tempo com os Kaingang e admira

3. Texto apresentado no relatório da Semana Cultural de 2006. 
a cultura de tal modo que considera estimulante a oportunidade de estudar a história e a cultura.

Todas as salas de aula da escola são utilizadas para diferentes tipos de exposições. As ervas medicinais são expostas com os nomes em Kaingang e em português e apresentam também as indicações e funções terapêuticas. $\mathrm{Na}$ entrada e nos corredores da escola, é exposto o artesanato Kaingang produzido pelos moradores da Terra Indígena e pelos alunos da Escola. Nesse espaço, é possível comercializar o artesanato, além de expô-lo como constituinte da cultura.

Para a degustação da culinária típica, foram construídas cabanas de madeira com cobertura de folhas de palmeira. $O$ fogo é feito no chão com pedaços de madeira, a maioria dos troncos é de tamanho médio. $O$ tamanho da madeira é justificado para representar o modo de vida do passado, quando a lenha, geralmente, durava a noite toda. As explicações são realizadas por famílias Kaingang da TI que, voluntariamente, passam o dia nas cabanas. Sobre o fogo (chamado de borralho) fica uma panela suspensa, que comporta feijão ou mandioca, também havia carne assando, que representava a carne de caça; no entanto, informaram que a carne hoje é oriunda de animais domésticos, em especial a carne suína. Na cinza são assados a batata doce, o pinhão ${ }^{4}$ e o bolo, este último tem sido o carro-chefe da degustação. Segundo as informantes, existem cinco tipos de receita do bolo na cinza; a receita tradicional apresenta os seguintes ingredientes: farinha de milho ou trigo, água e sal. Depois de misturar os ingredientes, eles são enrolados em uma folha de bananeira, a qual deve ser verde, "precisa ser a segunda folha". Feito isso, o bolo é enterrado na cinza e lá permanece por trinta minutos. A movimentação maior nas cabanas, as filas são o sinal de que o bolo saiu do forno.

Nas cabanas também havia uma exposição de alguns pratos, como pisé kumin $^{6}$ e folhas comestíveis e medicinais, como, por exemplo, urtigão, fuá, caraguatá, samambaia, kumin (folha de mandioca), caruru, rabanete etc.

Os professores indígenas realizaram filmagens com as pessoas mais "velhas", relatando o modo de vida Kaingang para ser exibido na Semana Cul-

4. Os Kaingang já foram denominados de pinares por viajantes que estiveram na região no passado. O nome lhes foi atribuído pelo fato de terem como base da alimentação os pinhões.

5. Milho cozido com cinza, posteriormente é socado em um pilão até se transformar em farinha.

6. Folha da mandioca, que é submetida a vários processos e depois cozida.

7. O termo "velho" não apresenta uma conotação pejorativa. A escola procura enfatizar e positivar o termo. 
tural. Todos afirmaram que as crianças, hoje, querem comida de supermercado e não se interessam muito pela comida dos antigos. Nesse caso, a Escola tem propiciado um espaço para que os visitantes degustem a culinária típica e, do mesmo modo, efetivado a possibilidade das crianças Kaingang se apropriarem desta culinária.

Na pesquisa "Olhares sobre a Terra Indígena Xapecó"; (Savoldi, 2006), foi possível perceber que as visitas demarcavam espaços de diálogo entre os visitantes e nativos. A concepção de autenticidade gerou inúmeros questionamentos, pois os olhares sobre a Terra Indígena têm revelado estranhamentos, tanto internamente, no reconhecimento da história que transcendia a memória experienciada pelo grupo indígena, quanto externamente, na constatação da semelhança. $\mathrm{O}$ olhar capta a semelhança ao perceber que a alteridade não corresponde ao modelo estereotipado das representações que foram construídas no passado.

A Semana Cultural na Terra Indígena Toldo Chimbangue apresenta um caráter educativo, o momento do encontro entre nativos e visitantes tem servido para que a própria população indígena possa expressar tudo o que vem pesquisando, revitalizando sobre sua cultura. Segue relato da aluna indígena Carla de Oliveira sobre a importância da Semana Cultural,

O objetivo da Semana Cultural é mostrar para os visitantes que a nossa história continua, e, mesmo sendo criticados, vamos mostrar, ainda mais, de que somos capazes para defender a nossa origem, e também para mostrar que a história do Toldo Chimbangue ainda é viva, e que no passar dos anos vamos continuar mostrando nossos rituais. (Aluna da oitava série da Escola E. E. F. Fen'Nó, Carla de Oliveira).

Uma professora visitante, responsável por uma turma de quarta série do Ensino Fundamental, relatou que é interessante trazer as crianças para que elas conheçam os índios pessoalmente e não apenas pelos livros. A professora falou que gostaria que as apresentações fossem diferentes a cada ano, pois informa já ter visto uma dança se repetir.

Os organizadores do evento afirmam que um dos objetivos é inovar, aprimorar a cada ano, mas, no entanto, não é possível criar uma dança nova a cada ano. 
No ano de 2006, foi realizada a VI Semana Cultural, o tema central foi"história viva do Toldo Chimbangue". A atividade que marcou a semana foi uma peça de teatro encenada pelos alunos. $\mathrm{O}$ texto narrado e encenado abordava a história dos Kaingang dividida em três atos. $\mathrm{O}$ primeiro ato abordava o dia-a-dia harmonioso antes da chegada dos portugueses. $\mathrm{O}$ segundo ato relatava os primeiros conflitos provocados pela Lei de Terras de 1850. O terceiro ato explicava a luta pela retomada da terra. Exibir essa versão da história para os não-índios foi considerado fundamental para professores e moradores da TI.

Nos mesmos moldes da TI Toldo Chimbangue, outras terras indígenas estão realizando a experiência da Semana Cultural, com diferentes dinâmicas, rituais, como, por exemplo, ritual de casamento Kaingang, exposição de armadilhas de caça e inclusive baile de encerramento com concurso de beleza indígena.

Chambers (2000) considera que o turismo cria espaços para a diferença, ele necessita da diferença e da constante renovação. Adverte, ainda, sobre a importância de estudar as particularidades do turismo em cada contexto e que o mesmo não deve ser percebido unicamente como uma questão econômica. Considera, também, que devemos estar atentos para os possíveis encontros que o turismo propicia.

No encontro das diferentes etnias, é possível perceber que elas lidam de maneira peculiar com o tempo, a história, e, da mesma forma, qualificam o patrimônio de acordo com seus valores. A memória é selecionada no sentido de revelar apenas os aspectos que os grupos consideram importantes e dignos. Halbwachs (1990), em sua obra "A memória coletiva”, destaca que o passado é sempre reconstruído, de acordo com os conflitos, tensões, normas e problemáticas do presente. A distinção que estabelece entre memória e história evidencia que a memória é referendada pelos quadros sociais que emolduram fatos e acontecimentos que o grupo partilha, já a história seria o quadro de acontecimentos que transcende a experiência e a percepção do grupo.

A realização das Semanas Culturais seleciona aspectos da cultura Kaingang considerados relevantes, como a divisão das metades clânicas e a retomada dos nomes na língua materna. Para Nacke (2007, p.35), "os Kaingang, como outros grupos da família lingüística Macro-Jê, organizam sua sociedade em metades exogâmicas, denominadas Kamé e Kairu, que mantêm entre si relações assimétricas e complementares". Segundo a autora, o mito de origem Kaingang considera Kamé e Kairu como seus ancestrais. As metades organizam a distri- 
buição dos papéis em diferentes rituais. No ritual do Kiki, culto aos mortos, os representantes das suas metades são classificados também a partir das pinturas faciais, riscos para os Kamé e cículos para os Kairu. Os nomes indígenas são herdados da metade à qual pertence o pai. Após o ritual do Kiki é possível mencionar e reutilizar os nomes dos mortos. Sobre isso, Nascimento (2001) afirma que

[...] o nome, para o Kaingang, não só identifica a pessoa como a representa. É a alma e o espírito. Talvez por esse motivo, raramente alguém revela seu nome indígena. Ultimamente, porém, as lideranças representativas da comunidade, em ações reivindicatórias, fazem questão de externar seu nome indígena como comprovante de sua identidade étnica (p. 54).

Na VIII Semana Cultural de 2008, houve o tema: "a realidade indígena no oeste catarinense". No último dia do evento aconteceu o benzimento e o batismo Kaingang. Durante o batizado, foi tornado público o nome Kaingang das pessoas que receberam o batismo. Neste momento, foi possível presenciar o interesse de alguns visitantes não-índios que manifestavam simpatia à cultura expressarem o interesse em receber o batismo, que foi prontamente atendido pelo kuiã (Kuja). O nome Kaingang era revelado com orgulho após o batismo.

A realização do batismo na Semana Cultural foi sugerida pelos professores e lideranças indígenas que intencionavam motivar a juventude a entender e valorizar esse ritual dos ancestrais. $\mathrm{O}$ kuiã advertiu que o batismo tem como objetivo proteger contra doenças e definir o nome verdadeiro.

O projeto de revitalização cultural acionado a partir da proposta do currículo diferenciado chamou a atenção para várias práticas culturais do passado que já não vinham sendo vivenciadas por boa parte do povo da Terra Indígena e hoje são expressas para os visitantes com orgulho. A esse respeito considero relevante a noção de tradição inventada desenvolvida por Hobsbawm e Ranger (1983), que consideram tradição inventada as tradições que apresentam elaborações recentes, mas que, no entanto, são mostradas como sendo antigas. Nesse sentido, Grunewald (2001, p.134) faz referência à obra de Handler e Linnekin, que consideram: "tradição é inventada porque é necessariamente reconstruída no presente seletivamente, apesar do entendimento de alguns participantes de tais atividades como sendo preservação antes que invenção". 
Nessa perspectiva, é mais importante compreender qual o significado que os grupos atribuem hoje às suas tradições, passado, mitos, elaborações e re-elaborações, estetizações de práticas selecionadas para a exibição pública, do que propriamente investigar o caráter de sua autenticidade.

Considero pertinente a observação de Grunewald (1999, p.38), ao destacar que todas as experiências dos turistas

[...] são autênticas, pois são em si experiências turísticas - não importando, portanto, se um elemento cultural foi construído exclusivamente para a encenação numa arena turística ou se é imemorialmente tradicional e incorporado no mercado turístico como mais uma atração, o que importa é que faz parte daquela experiência.

Neste período observado, os visitantes têm dois momentos na programação da Semana Cultural, um que é livre, e os grupos se dividem e podem visitar espaços diferentes, as salas com exposições ou as cabanas com a culinária, o artesanato etc. No momento das apresentações como danças, teatros, rituais, todos são chamados para ocupar os lugares próximos ao palco para assistir às apresentações.

Nestes momentos, os grupos se reencontram e relatam as impressões sobre a visita. Comentam e comparam as experiências; pude presenciar uma jovem (não-índia) manifestar com orgulho o nome de batismo que recebeu. Do mesmo modo, um grupo que degustou o bolo na cinza, relatando aos companheiros que em vão foram até a cabana da culinária, e não encontraram mais a especiaria.

As manifestações mais recorrentes refletem a expectativa de encontrar um "grupo conservado em um passado glorioso". O depoimento de uma aluna universitária evidencia essa concepção: "a Terra Indígena está urbanizada, não se tem mais aquela tribo. A influência dos não-índios é muito evidente, muito da sua própria cultura foi perdida. Eles não agem conforme pensávamos" (aluna universitária visitante) ${ }^{8}$. A mudança cultural é concebida como sinônimo de perda e, portanto, percebida como negativa.

Há representações, menos recorrentes, que entendem melhor as atitudes dos Kaingang, desconstruindo a visão maniqueísta expressa de diferentes modos no contexto regional.

8. Entrevistas com alunos visitantes da Semana cultural. 


\section{Considerações finais}

A organização da memória e a reordenação da tradição, com renovação e reinvenção dos fatos para consumar a nova ordem, possibilita aos Kaingang repensar sua identidade, ressignificar valores. Tornar pública essa experiência implica conduzir o olhar, traçar uma linha condutora tanto no sentido cronológico como no dos mapas cognitivos que se quer imprimir. Cabe salientar que a leitura que os diferentes visitantes fazem não é homogênea. Mesmo que se procure ordenar os fatos para melhor legitimar a história para o olhar da alteridade, é necessária, inicialmente, uma apropriação interna, para posteriormente tornála pública.

Os protagonistas do projeto de revitalização cultural estão selecionando as tradições e experimentando essas práticas no cotidiano. $\mathrm{O}$ resultado reflete uma negociação constante, interna e externa. A etnicidade é construída relacionalmente neste contexto conflituoso. A Semana Cultural é arena onde as negociações de sentidos, as trocas e mudanças culturais são experimentadas.

Os encontros entre o povo Kaingang e os visitantes provocam reflexóes e reelaborações nas noções de alteridade, de história e cultura. Os professores indígenas acreditam que a Semana Cultural é a possibilidade de mostrar com dignidade a versão da história do ponto de vista Kaingang, deste modo, a cultura passa a ser positivada e valorizada num contexto em que historicamente foi negativada e desvalorizada.

\section{Referências}

Banducci JR, Álvaro; Barretto, Margarita (orgs.). Turismo e identidade local - Uma visão antropológica. Campinas (SP): Papirus Editora, 2001.

Barretto, Margarita."O imprescindível aporte das ciências sociais para o planejamento e compreensão do turismo". Horizontes antropológicos/ UFRGS, IFCH, PPGAS, Ano 9, n. 19, Porto alegre, 2003.

Barth, Fredrik. "Grupos étnicos e suas fronteiras" (p.186-227). In: Poutignat, Philippe; Jocelyne Streiff-Fenart. Teorias da Etnicidade. São Paulo: Editora UNESP, 1998.

Bloemer, Neusa Maria Sens et alii. Os Kaingang no oeste catarinense. Tradição e atualidade. Chapecó: Argos, 2007. 
Bloemer, Neusa Maria Sens; Nacke, anelise. "As áreas indígenas Kaingang no oeste catarinense". In: Bloemer, Neusa Maria Sens et alii. Os Kaingang no oeste catarinense. Tradição e atualidade. Chapecó: Argos, 2007.

Bourdieu, Pierre. "A identidade e representação: elementos para uma reflexão crítica sobre a idéia de região". In: Bourdieu, P. O poder simbólico. Rio de Janeiro: Bertrand-Brasil, p. 107-132, 1989.

Chambers, Erve (ed.). Native Tours. The anthropology of travel and tourism. Illinois: Waveland. 2000.

D'Angelis, Wilmar da Rocha. "Para uma História dos Índios do Oeste Catarinense”. Cadernos do CEOM, 10 anos de CEOM. Edição englobando Cadernos do CEOM nº. 1/8. Chapecó: UNOESC, 1989, p. 141-219.

Fernandes, Ricardo Cid. "Notícia sobre os processos de retomada de Terras Indígenas Kaingang em Santa Catarina”. In: <http://www.antropologiasocial.ufpr.br/publicacoes/publicacoes_vol42003.htm $>$.

Geertz, Clifford. A interpretação das culturas. Rio de Janeiro: Editora Guanabara, 1989.

Grünewald, Rodrigo de Azeredo. Os indios do descobrimento: tradição e turismo.Tese de doutoramento apresentada ao Programa de Pós-Graduação em Antropologia Social do Museu Nacional da Universidade Federal do Rio de Janeiro. 1999.

— "Turismo e o «regate» da cultura Pataxó". In: BAnducci JR, Álvaro; BARRETTO, Margarita (Orgs.). Turismo e identidade local - Uma visão antropológica. Campinas (SP): Papirus Editora, 2001.

Grupioni, Luís Donisete Benzi; Silva, Aracy Lopes da. A temática Indígena na Escola. Novos subsídios para professores de $1^{\circ}$ e $2^{\circ}$ graus. 2 ed. São Paulo: Global; Brasília: MEC: UNESCO, 1998.

Halbwachs, Maurice. A memória coletiva. São Paulo: Vértice Editora, 1990. Hobsbawm, E. J; Rager T. A invenção das tradiçóes. Rio de Janeiro: Paz e Terra, 1984.

Lac, Flávia. O turismo e os Kaingang da Terra Indígena de Iraí - RS. Dissertação de Mestrado, UFP, 20005.

Nacke, Anelise. "Os Kaingangः passado e presente”. In: Bloemer, Neusa Maria Sens et alii. Os Kaingang no oeste catarinense. Tradição e atualidade. Chapecó: Argos, 2007. 
Nascimento, Ernilda Souza do. Há vida na história dos outros. Chapecó: ARGOS, 2001.

Nötzold, Ana Lúcia. Nosso vizinho Kaingang. Florianópolis: Imprensa Universitária da UFSC, 2003.

Oliveira, João Pacheco de. Muita terra para pouco índio? Uma introdução (crítica) ao indigenismo a à atualização do preconceito. In: Grupioni, Luís Donisete Benzi; Silva, Aracy Lopes da. A temática Indígena na Escola. Novos subsídios para professores de $1^{\circ}$ e $2^{\circ}$ graus. 2 ed. São Paulo: Global; Brasília: MEC: UNESCO, 1998.

Oliven, Ruben George. Nação e tradição na virada do milênio. Resgateः Revista de cultura. São Paulo, n. ${ }^{\circ}$ 5, p. 77-87, 1993.

Piovezana, Leonel. Educação e cultura na Terra Indígena Xapecó. Dissertação de Mestrado. Santa Cruz do Sul: UNISC - Universidade de Santa Cruz do Sul. 2000.

SAvoldi, Adiles. "Olhares sobre a Terra Indígena Xapecó: municípios de de Ipuaçú e Entre Rios/SC". Cadernos do CEOM, ano 19 n. 24, Chapecó: Argos, 2006.

Steil, Carlos Alberto. "Antropologia e turismo". Horizontes antropológicos/ UFRGS. IFCH. PPGAS. Ano 9, n. 19. Porto alegre, 2003.

Veiga, Juracilda."Revisão bibliográfica crítica sobre a organização social Kaingang". Cadernos do CEOM, 10 anos de CEOM. Edição englobando Cadernos do CEOM, nº. 1/8. Chapecó: UNOESC, 1989. p. 141-219.

Vyjkág, Adão Sales et alii. Textos Kanhgág.1. ed. APBKG/Dka Áustria/ MEC/PNUD: Brasília , 1997. 